\title{
VALUE OF ABNORMAL RETINAL CORRESPONDENCE IN BINOCULAR VISION*
}

\author{
BY \\ M. LEVINGE \\ Birmingham and Midland Eye Hospital
}

ABNORMAL retinal correspondence has been a vexed subject since the physiology of binocular vision and strabismus have been discussed, but it seems to be generally accepted that it is an adaptation of the sensory relations of the retina to the squinting position.

Normal retinal correspondence is present when any pair of corresponding points have a common visual direction; abnormal retinal correspondence occurs when retinal areas which are ordinarily disparate prove to have a common visual direction (Swan, 1950).

At the onset of a squint, retinal correspondence is normal and projection is incorrect by an amount equal to the angle of deviation, but according to Duke-Elder (1950):

at a later stage the normal orientation centred on the macula may change, a perceptual correction is made, and projection becomes correct in spite of the deviation. In essence abnormal retinal correspondence is a mental re-orientation of the displaced image of one eye in binocular fixation to make allowance for its faulty position.

The extent of the ultimate value of -abnormal retinal correspondence is widely disputed. Javal (1868) concluded that it was a new system of reaction depending on awareness of the position of each eye with regard to the body; that each eye followed its own monocular projection in order to secure accurate location of objects. Verhoeff (1938) gives a similar opinion, and says that retinal correspondence does not exist in cases now classified by the term abnormal retinal correspondence. Duke-Elder (1950) states that " anomalous correspondence frequently takes no part in binocular vision and would seem to be biologically valueless". Burian (1941), on the other hand, maintains that it is an attempt of the organism to restore some semblance of binocular vision; a substitution for the normal of an abnormal reaction of a similar type.

This diversity of opinion presents a very baffling picture to orthoptists, and we have attempted to exorcise or to abolish abnormal retinal correspondence from the binocular function of the squinting patient, assuming that it cannot have a useful part in binocular vision. Our therapy has been singularly unsuccessful, and, since we are forced to accept this condition in a number of our patients, it would seem reasonable to attempt to assess its place in certain clinical findings which we have at our disposal.

INVESTIGATIONS

Abnormal retinal correspondence is a sensory adaptation to a particular motor

- Received for publication November 11, 1953. 
condition, and is acquired for the use of the eyes under ordinary conditions of seeing. It may function only under certain visual conditions, and therefore be manifest only when these are present. Normal correspondence may be suppressed completely or partially, and the extent to which that suppression functions depends upon the visual circumstances.

It will depend largely therefore on the method of investigation whether normal or abnormal response is demonstrated. Various tests may evoke different responses, or the same test may show varying responses at varying times. The more nearly the test is related to the ordinary conditions of seeing the more likely it is to elicit a response which shows the usual adaptation of the patient. If abnormal retinal correspondence exists in certain circumstances, it will be demonstrated only by tests which duplicate those circumstances. The innate normal correspondence is much more likely to become dominant if the patient is presented with an unusual visual image, depending on how deeply grounded is the anomalous correspondence.

The same individual's response to different tests may vary considerably, since each test assesses a different thing. For example, the after-image test demonstrates the projection of the two maculae in a field of uniocular vision, whereas the synoptophore, Maddox rod, and diplopia tests indicate the projection of the macula of one eye and the non-corresponding retinal area of the other eye, in a field of binocular vision.

Before proceeding with this investigation considerable thought was given to devising an additional test which would investigate projection under normal conditions of seeing, i.e. with a binocular visual field, without dissociation of the eyes by filters and without presentation of bizarre visual images. This proved to be impossible.

However a very simple apparatus was set up, remotely suggested by Burian's investigation of abnormal retinal correspondence. A system of polarized lenses was used. The patient looked through a pair of goggles containing polarized lenses and fixed an illuminated oblong, the upper portion so polarized that it could be seen only by the right eye, and the lower portion so polarized that it could be seen only by the left eye. Each section had a control mark.

Fig. 1.-It was considered that this would produce a minimum of interference with the normal visual circumstances. The method of investigation is not

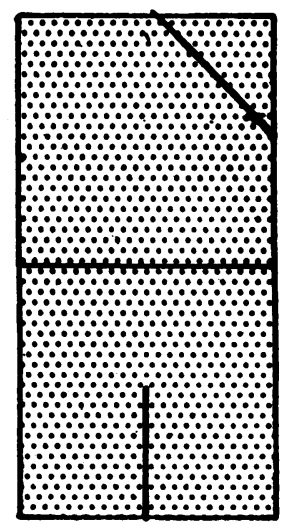

(a)

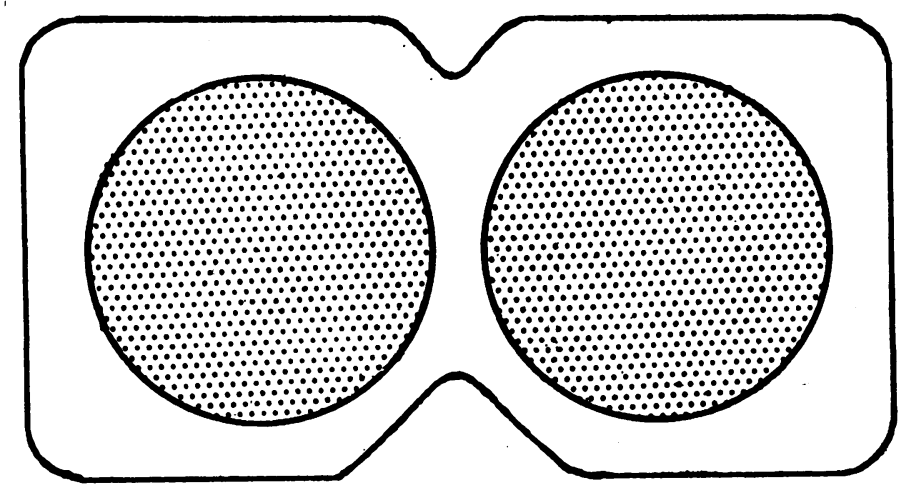

(b)

Fig. 1.-Projection test.

(a) Polaroid lens attachment

(b) Polaroid lens goggles 
complicated. The angle of deviation is measured by prism and cover test, and then the projection is investigated. One of the following responses may be elicited:

(1) If binocular single vision (B.S.V.) is present the oblong is seen complete, with two control marks.

(2) The presence of strabismus is demonstrated by one of the following:

(a) Normal retinal correspondence (N.R.C.).-The two sections are displaced corresponding to the angle of deviation.

(b) Abnormal retinal correspondence (A.R.C.).-The two sections are either displaced to a degree less than the angle of deviation, indicating unharmonious correspondence, or seen complete and undisplaced, indicating harmonious abnormal retinal correspondence. The angle of anomaly may be measured with prisms.

(c) Complete suppression of one image.-For future reference this will be called the "projection test".

Figs 2 and 3.-Since it was considered important to assess individual response on a variety of tests, the complete investigation included the following:

(1) Visual acuity test,

(2) Prism and cover test,

(5) Double-image test with red filter,

(3) Subjective cover test,

(6) Assessment of fusional response with prism test,

(4) After-image test,

(7) Assessment of physiological diplopia,

(8) Assessment of binocular convergence,

(9) Synoptophore test.

The synoptophore investigation included measurement of the subjective and objective angles of deviation with foveal, macular, and paramacular slides, and with the deviation corrected by prisms. Fusion, ductions, and stereopsis with numbered slides were tested, and an attempt was made to assess the possible degree of visual acuity. It is said that, if abnormal retinal correspondence is a binocular condition, it must incur the conjunctive use of the high grade visual area of the macula with one of low grade visual response, and it was considered that it would be interesting to assess this. An attempt was therefore made to do so in this manner:

Slides of Snellen's test type were used and the patient was instructed to fix a letter on the line of maximum visual acuity. The illumination was decreased for each eye in turn, and the amount of illumination required for recognition of the visual image was recorded from the rheostat controls.

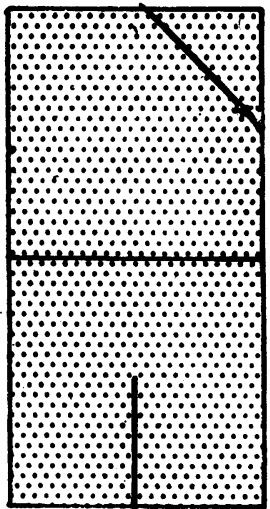

(a)
Distance A to $B$ is equal to the angle of deviation.
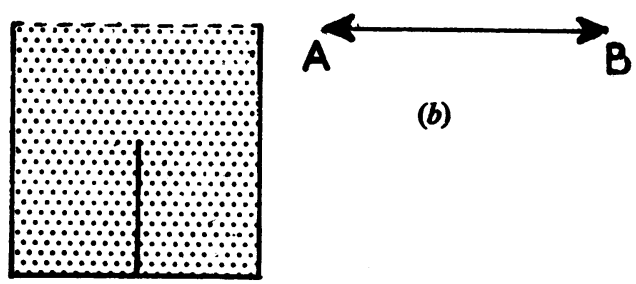

(b)

\section{$B$}

FIG. 2.-Responses elicited by projection test.

(a) With binocular single vision

(b) Squint with normal retinal correspondence

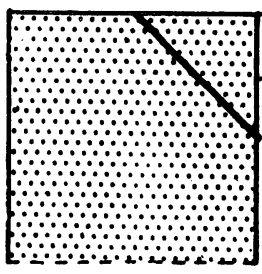


Four groups of patients were investigated (see Table):

(A) Forty cases (taken at random from the current files) which were diagnosed on the synoptophore as lacking normal retinal correspondence (L.N.R.C.)*

(B) 58 cases of abnormal retinal correspondence (A.R.C.). These were discharged as cosmetically satisfactory in 1952 and 1953, or taken from the current files.

(C) 34 cases (made up as above) of small degrees of esotropia in which there had been doubt as to the state of binocular function.

(D) Twenty cases (taken at random from those discharged as cured in 1953) which used to squint but now had binocular single vision (B.S.V.).

The investigation was planned to give information on the following points:

(1) Age at onset of squint (Table, Section 1).

(2) Type of deviation (Table, Section 2).

(3) Influence of refractive errors (Table, Section 3).

(4) Degree of binocular vision (Table, Section 4).

(5) Response to various tests (Table, Section 5).

(6) Angle of anomaly (Table, Section 6).

(7) Relationship of abnormal retinal correspondence to amblyopia (Table, Section 7).

(8) Assessment of visual acuity (Table, Section 8).

(9) Response of abnormal retinal correspondence to orthoptic and surgical treatment (Table, Sections $9 a$ and $b$ ).

(10) Presence of symptoms ((Table, Section 10).

(11) Physical and mental dexterity (Table, Sections 11a-c).

\section{RESULTS}

\section{(1) Average Age at Onset of Squint}

These results demonstrated the accepted conclusion that the ultimate degree of binocular function is dependent upon the age at onset of squint. Those lacking binocular functions showed the earliest age of onset, and those attaining binocular single vision, the latest. It is of interest to note that those cases found to have

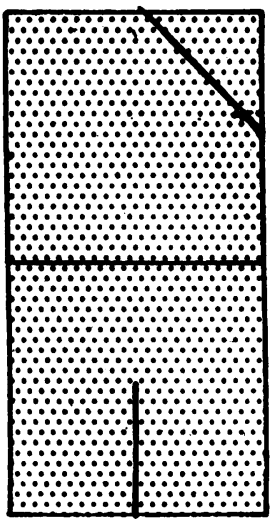

(a)
Distance $A$ to $B$ is not equal to the angle of deviation.

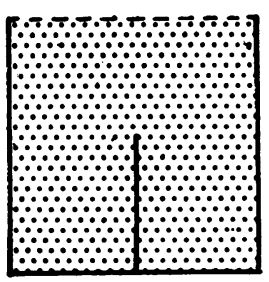

(b)

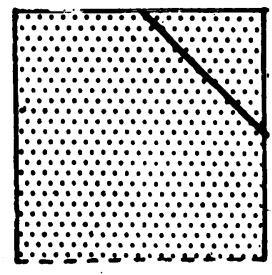

FIG. 3.-Responses elicited by projection test.

(a) Squint with harmonious abnormal retinal correspondence

(b) Squint with unharmonious abnormal retinal correspondence

*Except where otherwise stated Group A gave normal responses to other tests. 
anomalous correspondence had a somewhat later age of onset than those lacking binocular functions (Fig. 4, p. 341).

(2) Type of Deviation

There was an overwhelming proportion of convergent squints in all groups

TABLE

RESULTS OF INVESTIGATIONS

\begin{tabular}{|c|c|c|c|c|c|c|}
\hline \multicolumn{3}{|c|}{ Aspect of Investigation } & $\begin{array}{c}\text { (A) } \\
\text { Lacking } \\
\text { Normal Retinal } \\
\text { Correspondence }\end{array}$ & $\begin{array}{c}\text { (B) } \\
\text { Abnormal } \\
\text { Retinal } \\
\text { Correspondence }\end{array}$ & $\begin{array}{c}\text { (C) } \\
\text { Esotropia }\end{array}$ & $\begin{array}{l}\text { (D) } \\
\text { Binocular } \\
\text { Single } \\
\text { Vision }\end{array}$ \\
\hline \multicolumn{3}{|l|}{ Number of Cases } & 40 & 58 & 34 & 20 \\
\hline \multicolumn{3}{|c|}{ (1) Average Age at Onset of Squint (yrs) } & $1 \cdot 7$ & $2 \cdot 75$ & $2 \cdot 75$ & $3 \cdot 6$ \\
\hline \multirow{7}{*}{$\begin{array}{l}\text { (2) Type of Devi- } \\
\text { ation (per cent.) }\end{array}$} & \multicolumn{2}{|l|}{ R.C.S. } & 44 & 31 & 55 & 35 \\
\hline & \multicolumn{2}{|l|}{ L.C.S. } & 23 & 53 & 41 & 50 \\
\hline & \multicolumn{2}{|l|}{ A.C.S. } & 33 & 13 & one case & 10 \\
\hline & \multicolumn{2}{|l|}{ L.D.S. } & - & one case & 一 & 1 case \\
\hline & \multicolumn{2}{|c|}{ Accommodative } & - & Elem & ent 23 & 50 \\
\hline & \multicolumn{2}{|l|}{ Intermittent } & - & 3 & 5 & 25 \\
\hline & \multicolumn{2}{|l|}{ Constant } & 100 & 89 & 72 & 25 \\
\hline \multirow{4}{*}{$\begin{array}{l}\text { (3) Refraction (per } \\
\text { cent.) }\end{array}$} & \multicolumn{2}{|l|}{ Hypermetropic } & 90 & 82 & 88 & 90 \\
\hline & \multicolumn{2}{|l|}{ Myopic } & one case & one case & 一 & - \\
\hline & \multicolumn{2}{|l|}{ Anisometropic } & - & three cases & one case & - \\
\hline & \multicolumn{2}{|l|}{ Emmetropic } & one case & 7 & three cases & two cases \\
\hline \multirow{7}{*}{$\begin{array}{ll}\text { (4) Degree } & \text { of Bi- } \\
\text { nocular } & \text { Vision } \\
\text { Present } & \text { (per } \\
\text { cent.) } & \end{array}$} & \multicolumn{2}{|l|}{ Fusion } & one case & 94 & 97 & 100 \\
\hline & \multicolumn{2}{|c|}{ Suppression of Fusion } & 98 & two cases & one case & - \\
\hline & \multicolumn{2}{|c|}{ Adduction (average degree) } & to $5^{\circ}$ & to $9.9^{\circ}$ & to $9 \cdot 5^{\circ}$ & to $18 \cdot 5^{\circ}$ \\
\hline & \multicolumn{2}{|l|}{ Stereopsis } & Nil & 58 & 76 & 90 \\
\hline & \multicolumn{2}{|c|}{ Physiological Diplopia } & 22 & 62 & 79 & 85 \\
\hline & \multicolumn{2}{|c|}{ Fusional Movement } & 22 & 50 & 69 & 70 \\
\hline & \multicolumn{2}{|c|}{ Binocular Convergence } & 77 & 91 & 97 & 100 \\
\hline \multirow{16}{*}{$\begin{array}{l}\text { (5) Response to } \\
\text { Tests (per cent.) }\end{array}$} & \multirow[t]{3}{*}{ Double Image } & N.R.C. & 40 & & 100 & 100 \\
\hline & & A.R.C. & 55 & 100 & - & 一 \\
\hline & & Suppression & one case & - & - & - \\
\hline & \multirow{3}{*}{ After Image } & N.R.C. & 45 & 34 & 79 & 80 \\
\hline & & A.R.C. & 40 & 38 & one case & two cases \\
\hline & & Not observed & 15 & 28 & 17 & two cases \\
\hline & & N.R.C. & 25 & - & 47 & 75 \\
\hline & Projection & A.R.C. & 30 & 82 & - & - \\
\hline & & Suppression & 45 & 18 & 53 & 25 \\
\hline & & N.R.C. & 30 & 22 & 32 & 35 \\
\hline & Cover & A.R.C. & 20 & 34 & 20 & 一 \\
\hline & & Suppression & 50 & 44 & 48 & 65 \\
\hline & & N.R.C. & - & 8 movement & 59 movement & 100 \\
\hline & Synoptophore & A.R.C. & - & 89 & 41 & - \\
\hline & & L.N.R.C. & 100 & 1 & 一 & 一 \\
\hline & Recovery Flic & ker & 15 & 60 & - & - \\
\hline
\end{tabular}


TABLE-continued

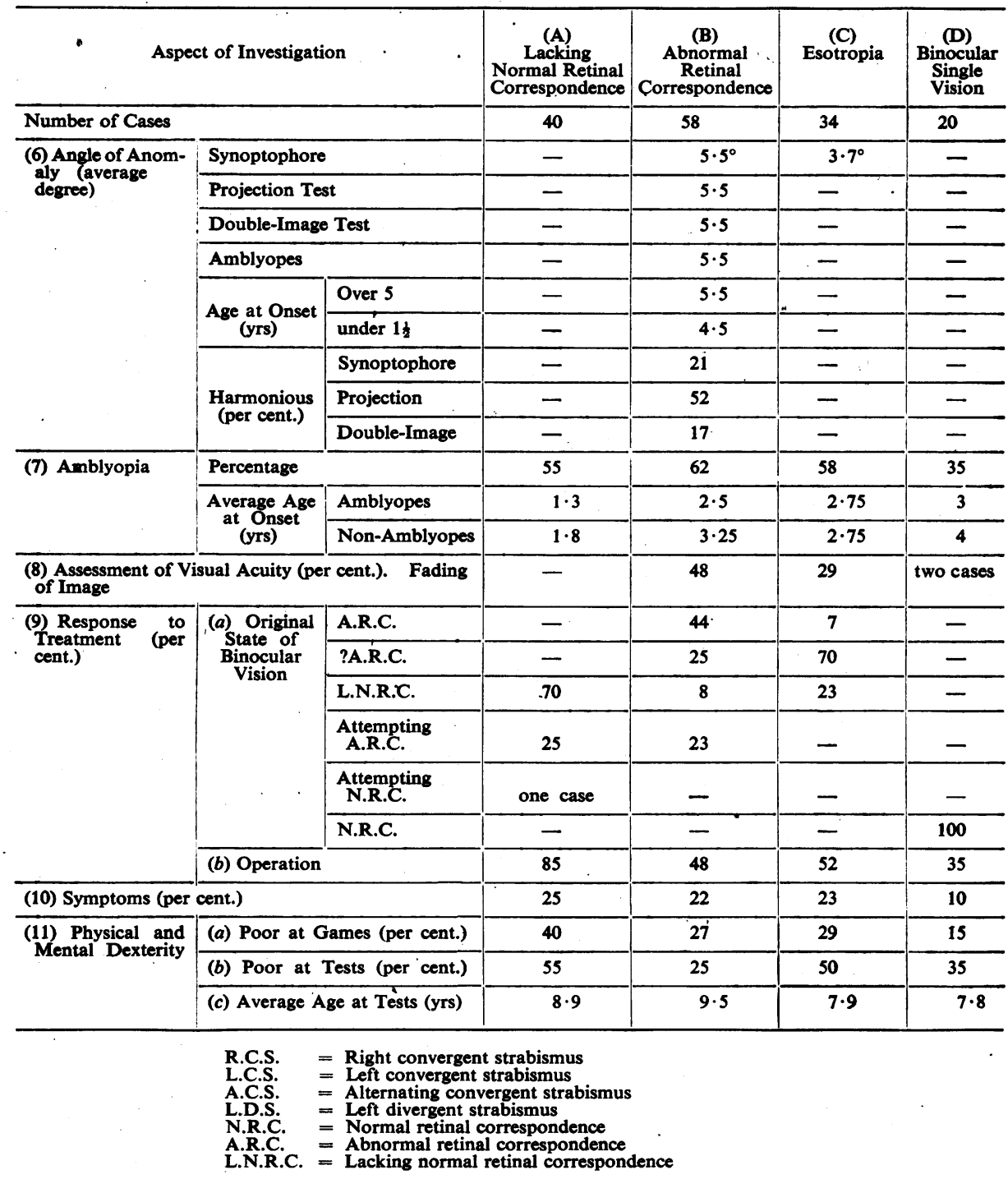

but fewer alternators in the anomalous correspondence group than in those lacking binocular function; there was an increasing proportion of accommodative type and intermittent squints, as the degree of binocular function increased. In Group B the size of the deviation was not of particular significance in cases of early or late onset, or in cases originally showing amblyopia.

(3) Influence of Refractive Errors

The greatest proportion in all groups were hypermetropic.

(4) Degree of Binocular Vision

Group A all lacked a subjective angle with simultaneous macular perception 
slides of the three stated sizes. One case superimposed fusion slides, although this test had not previously been used.

Group B all demonstrated some ability to fuse synoptophore slides except two patients.

In all groups, as one would expect, the amount of adduction increased with the degree of binocular function.

The increased proportion of binocular response in these groups is worthy of notice. Fusional movement depended upon the presence of physiological diplopia, but not all cases with physiological diplopia showed fusional movement.

(5) Response to Various Tests

In Group A are included here all patients demonstrating both normal and abnormal correspondence but lacking correspondence on the synoptophore). The synoptophore did not elicit retinal correspondence in these cases, but with the exception of one patient, all demonstrated that this was present on the double-image test. All patients in this group gave a synoptophore response which corresponded with diagnosis on other tests. That is to say, if anomalous correspondence was demonstrated on other tests they "crossed false" on the synoptophore; if normal correspondence was elicited, they "crossed true" on the synoptophore. A high projection suppressed one image completely on the projection test.

In Group B 100 per cent. responded anomalously on the double-image test. The projection test showed a much smaller proportion of suppression response than in Groups $A$ and $C$. The after-image test and subjective cover test gave varying results. The synoptophore largely demonstrated anomalous correspondence.

In Group $\mathrm{C}$ the double-image test gave a 100 per cent. response with normal correspondence. The after-image test gave a high proportion with normal response. The projection test gave a majority response of suppression, higher than in Group A and greatly in excess of Group B. The synoptophore diagnosis was uncertain in many cases; that is, a movement occurred on cover testing, but one could not definitely demonstrate an angle of anomaly. However, in some cases (41 per cent.), a definite angle of anomaly was recorded.

In Group $D$ all patients gave normal responses on the double-image test, synoptophore, and projection test, except that 25 per cent. suppressed one image in the last.

The recovery flicker on cover test could be clearly demonstrated in many cases in Group B. The deviating eye which takes up fixation on covering the other eye will, on removal of the occluder, deviate again to the maximum degree, and then partially recover fixation, to a degree which appears to correspond to that of the angle of anomaly. This recovery flicker may be seen on fixation of either eye, and should not be confused with the cover-test of fixation disparity, thus defined by Scobee (1952):

If the right eye is covered there is a slight movement of the left eye to take up foveal fixation. If the left eye is covered there is no movement of the right eye since that is already in the position of foveal fixation.

The patients in Group A shown to have a recovery flicker on cover test all gave anomalous responses on other tests.

(6) Angle of Anomaly

In Group B the average angle of anomaly was constant at $5 \cdot 5^{\circ}$ on all tests. 
The greatest was $11^{\circ}$, the least $2^{\circ}$. A greater proportion showed harmonious abnormal retinal correspondence on the projection test, than on any other. The age of onset appeared to have little bearing on the angle of anomaly. Those with early or late onsets still showed the average degree, and the same applied to amblyopia.

In Group $\mathrm{C}$ the angle of anomaly in .cases which gave a definite subjective and objective measurement on the synoptophore was smaller than that shown in Group B. The greatest was $6^{\circ}$, the least $2^{\circ}$.

(7) Relationship of Abnormal Retinal Correspondence to Amblyopia

In Group A the lowest original degree of amblyopia was 2/60. All patients improved with occlusion, and none deteriorated. The average age of onset was $1 \cdot 3$ years, and of the non-amblyopes in Group A, 1.8 years.

In Group B the proportion was very slightly higher than in Group A. The lowest visual acuity was $1 / 60$. 10 per cent. failed to improve with occlusion. All other patients showed and successfully maintained improvement. Fourteen amblyopes and twelve non-amblyopes had abnormal retinal correspondence of the harmonious type. The average age at onset of the amblyopes was $2 \frac{1}{2}$ years, and of the non-amblyopes $3 \frac{1}{4}$ years.

In Group $\mathrm{C}$ there was a smaller proportion of amblyopes than in Group B. The lowest visual acuity was $1 / 60$. All patients improved with occlusion, but one deteriorated after discharge. The, average age of onset for both amblyopes and non-amblyopes was 2.75 years.

In Group D there was marked decrease in the proportion of amblyopes. The lowest visual acuity was 6/60. All patients achieved and maintained improvement with occlusion. . The average age at onset of amblyopes was 3 years and of nonamblyopes 4 years.

(8) Assessment of Visual Acuity.

The attempted assessment on the synoptophore appeared to indicate that patients in Group B retained the visual image for a shorter time on decrease of illumination. Only in 19 per cent. did this appear to be associated with any degree of amblyopia. Two adults when using the synoptophore could superimpose images using either an anomalous or a normal correspondence at will, the distinguishing factor being that the images were brighter when using normal correspondence.

(9) Response of Abnormal Retinal Correspondence to Orthoptic and Surgical Treatment

(a) Original State of Binocular Vision.-In Group B those patients who were originally diagnosed as having abnormal retinal correspondence retained this after orthoptic treatment ( 44 per cent.). The remainder showed a positive abnormal retinal correspondence when diagnosis was complete after several orthoptic sessions.

(b) Operation.-In Group B, of the 48 per cent. who received surgical treatment, all except one maintained a satisfactory post-operative result. This exception showed an increase of $8^{\circ}$ in the angle of deviation when reviewed after discharge.

The same pre- and post-operative angles of anomaly were maintained in 27 cases. The pre-operative angle of anomaly was adapted post-operatively to the new angle of deviation. No case developed normal correspondence 
post-operatively, or changed from the harmonious to the unharmonious type. The one exception showed a decrease of $5^{\circ}$ in the post-operative angle of anomaly.

(10) Presence of Symptoms

These included very few complaints of malprojection and clumsiness at the onset of squint; some occasional diplopia and poor stereopsis; some difficulty with close work. The percentage decreases markedly in Group D.

(11) Physical and Mental Dexterity

(a) Games.-The greatest difficulty was apparently experienced by patients in Group A; it was less in Groups B and C and least in Group D.

(b) Intelligence.-This was superficially assessed, and note made of the patient's difficulty in performing the tests (Fig. 5). It is reasonable to expect this to give some indication of the individual's capabilities, since all were familiar with the synoptophore test, and none had previously practised with the additional tests. The most successful were those in Group B.

(c) Age at Time of Test.-The patients tested were of comparable age groups.

Discussion

Of the diagnostic tests used, the double-image test appeared to record most accurately the state of retinal correspondence. But this is not an ideal method, since the red filter may dissociate the test from normal visual conditions, which is indicated by the fact that fewer cases showed harmonious abnormal retinal correspondence on this and the synoptophore test, than on the projection test where visual circumstances were more usual. Abnormal retinal correspondence of the harmonious type is the ideal adaptation, and it must be considered that this state may be demonstrated in many, if not in all, patients with anomalous correspondence, if investigations duplicate the usual visual conditions.

The after-image test showed variable responses. Some patients who reacted abnormally on the double-image, projection, and synoptophore tests, gave a normal response on the after-image test. Perhaps this happens because the after-image test assesses only the projection of the two maculae when tested in the uniocular visual fields, whereas the other tests assess non-corresponding retinal areas in the binocular visual field? The first response may be one of innate normal retinal correspondence; the second demonstrates the adaptation of the patient in normal vision. An anomalous response on the afterimage test may indicate that abnormal retinal correspondence is well grounded and normal correspondence suppressed completely. If normal correspondence is elicited only on this test, it may follow that anomalous correspondence is not completely dominant, and that normal correspondence will function in unusual circumstances.

The synoptophore appeared to be inadequate in the diagnosis of small degrees of esotropia. It is maintained that in these cases where diagnosis of binocular function on the synoptophore is in doubt (i.e. it is not certain whether they have abnormal retinal correspondence or normal retinal correspondence with a small degree of intense suppression), it is essential to employ additional tests. Only in this way can a differential diagnosis be made. Some patients in this group (41 per cent.) gave definite objective and 
subjective readings on the synoptophore; others merely recorded movement on the synoptophore cover-test; but all gave normal responses on the doubleimage test, and most of them on the after-image test (79 per cent.). It is interesting to notice that more than half (53 per cent.) showed complete suppression of one image on the projection test, and that the group with abnormal retinal correspondence included only 18 per cent. with suppression. This would indicate a more intense suppression in esotropia of a small degree. The average angle of anomaly was smaller in the esotropic group $\left(3 \cdot 7^{\circ}\right)$ than in the group with anomalous correspondence $\left(5 \cdot 5^{\circ}\right)$, although the latter is considerably smaller than many authorities have considered typical.

The synoptophore was diagnostically inadequate in patients with large areas of intense suppression. Such patients were more successfully investigated by other methods; 95 per cent. could be assessed on the double-image test, but the after-image and projection tests were more restricted by suppression. About 50 per cent. suppressed on these tests, but this figure compares favourably with the 100 per cent. suppression on the synoptophore. It cannot be said, therefore, that a patient lacks normal retinal correspondence merely because this faculty cannot be demonstrated on the synoptophore.

It would appear that the conditions necessary for the development of abnormal retinal correspondence must be youth, adaptability, a consistent angle of deviation, and perhaps the existence of some binocular function before the onset of squint. The series did not include one case of strabismus acquired in adult life, the highest age of onset being 6 years.

Fig. 4 shows that the average age of onset was 2.75 years, falling midway between those said to lack normal retinal correspondence (Group A), and those who had attained binocular single vision (Group D).

The patients in Group B performed the tests with the least difficulty, and if this can be accepted as some measures of their mental capabilities, they were more adaptable and responsive than the control (Fig. 5).

The greatest proportion of patients had constant convergent squints. Only 8 per cent. showed any mobility of deviation and only 3 per cent. were intermittent. 13 per cent. alternated, a surprising low proportion in view of the prevalent opinion that abnormal retinal correspondence is more common in alternating squint.

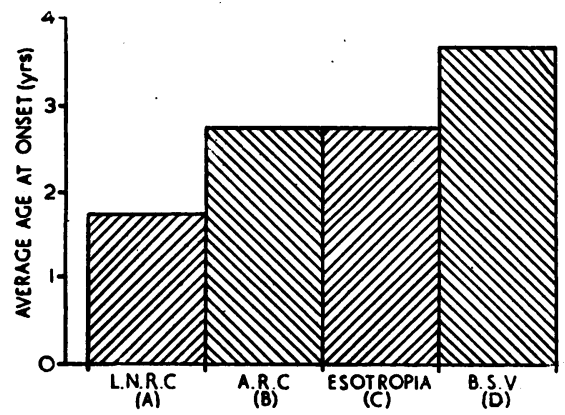

FIG. 4.-Average age at onset of squint.

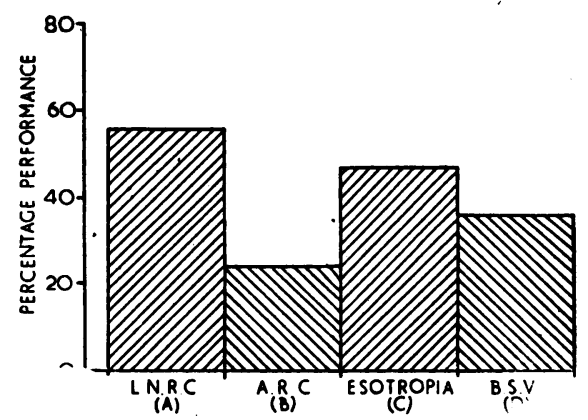

Fig. 5.-Degree of difficulty experienced in performing tests. 
Abnormal retinal correspondence appears to have a reasonable place in binocular vision. Without doubt those patients investigated with abnormal retinal correspondence had a higher degree of binocular response than those lacking a positive anomalous correspondence (Fig. 6).

Stereopsis, physiological diplopia, fusional movements, and binocular convergence were present to a greater degree. The anomalous group seemed to have established a positive upward movement towards binocular single vision. That abnormal retinal correspondence is indeed a binocular condition

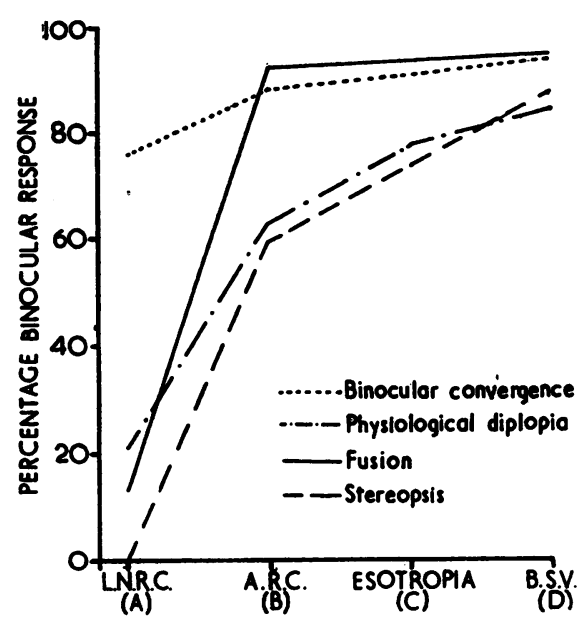

Fig. 6.-Degree of binocular response. and not solely a uniocular adaptation of projection seems to be demonstrated by several adult patients, all of whom attended with ocular symptoms associated with near work. These proved on investigation to have small convergent squints with abnormal retinal correspondence. The symptoms were relieved on increase of binocular convergence, using the anomalous correspondence as a basis for training.

One of these patients, an intelligent, accurate observer, had noticed great difficulty in driving and playing tennis, when on a previous occasion he had been forced to be uniocular for a time. In this case, anomalous correspondence was extremely well grounded; it was demonstrable on all tests, and was of the harmonious type.

Patients with abnormal retinal correspondence have a greater field of vision than those with a large strabismus lacking the adaptation of anomalous correspondence.

A girl aged 16 years, with a constant alternating divergent squint, was found to have complete suppression on the synoptophore, but normal retinal correspondence was elicited on other tests. She stated that her visual field was controlled in this manner. When looking to the left, she úsed her left eye; when looking to the right, she used her right eye; the central field of vision was shared by either eye alternatively, whichever was the more convenient. The visual field of the non-fixating eye was always suppressed and when alternation occurred, she experienced a momentary loss of vision whilst fixation changed from one eye to the other. There was no binocular visual field.

A patient with abnormal retinal correspondence not only has a binocular area of visual field, but also, since the deviating eye is not completely suppressed, a larger available field of vision.

Perimeter charts of binocular visual fields were made for three patients: one with binocular single vision, one displaying convergent squint associated with abnormal retinal correspondence, and one showing a convergent squint with normal correspondence, but lacking retinal correspondence on the synoptophore. 
The child with abnormal retinal correspondence proved to have a field of vision comparable with that of binocular single vision, but the child lacking anomalous function had a field of vision smaller by $9^{\circ}$ left, $3^{\circ}$ right, $5^{\circ}$ elevation, and $2^{\circ}$ depression.

It is stated by some authorities that abnormal retinal correspondence is rarely associated with amblyopia. This did not appear to be the case, and the presence or otherwise of amblyopia seemed to be determined by the age of onset, cases of abnormal retinal correspondence with amblyopia having an earlier age of onset than those without amblyopia.

Amblyopia is not affected by the degree of adaptation achieved; it was present equally in harmonious and unharmonious abnormal retinal correspondence. Patients with amblyopia did not demonstrate a variance of the size of the angle of anomaly, nor had the original angle of deviation any significance.

There appeared to be little foundation for the view that anomalous correspondence is an unfavourable condition in surgical prognosis. Only one patient showed a small increase in the size of the post-operative deviation when reviewed at a later date, and certainly there was no indication that these patients revert post-operatively to their original angle of deviation in order to utilize the established anomalous correspondence; the angle of anomaly is always adapted post-operatively to the new angle of deviation.

It is considered that orthoptic treatment is valueless in overcoming abnormal retinal correspondence. In no instance was normal correspondence successfully re-established, although treatment was most painstakingly carried out in a large number of cases, and all therapeutic methods adopted. Whether, in view of the previous findings, it is desirable to negate this correspondence is questionable; it seems that much time and effort is wasted in attempting to re-awaken normal correspondence. Such an attempt is not only unrewarding but misguided, since the patient is more fortunate in having the positive advantage of anomalous correspondence, than in experiencing the negative condition of complete suppression.

Abnormal retinal correspondence has been used as a basis for treatment at the Birmingham Eye Hospital for the past 18 months. It has been found to be beneficial in the treatment of adult patients with anomalous correspondence and poor binocular convergence, permitting the anomalous correspondence to function. A number of patients have been treated post-operatively in this way; abnormal retinal correspondence has been consolidated and used as a basis for adduction and abduction, and for binocular exercise off the synoptophore. This has been helpful in establishing comfortable binocular functions for the patient in every-day visual circumstances.

It is suggested that the routine treatment of strabismus associated with abnormal retinal correspondence should be:

(1) To overcome amblyopia by occlusion.

(2) To correct the deviation by surgery where this is cosmetically indicated.

(3) To attempt to consolidate the result, using anomalous correspondence, where it is sufficiently grounded, as a basis for orthoptic treatment. 


\section{CONCLUSIONS}

Abnormal retinal correspondence is a physiological part of normal binocular vision in many persons and is a natural accompaniment of the binocular adjustment when the visual axes are not parallel in all positions.

It is a binocular condition and not a uniocular adaptation of projection. That the anomalous projection should be fully adapted and therefore harmonious is admitted, but it is suggested that, since the phenomenon occurs only in free vision, present methods of investigation fall short in their duplication of normal visual conditions, and that the resulting responses may be an inaccurate indication of the patient's true degree of adaptation.

Abnormal retinal correspondence does not create an unfavourable surgical prognosis, but it cannot be eradicated by orthoptic treatment or replaced by normal correspondence. It is a condition to be encouraged and attempts to eliminate it are based on a faulty appreciation of its value and purpose.

I should like to thank Mr. P. Jameson Evans for help and advice both in the planning of investigations and in the writing of this paper, Mr. J. H. Doggart for advice on presentation of the findings, and the medical staff of the Birmingham and Midland Eye Hospital for the use of clinical material.

\section{REFERENCES}

Burian, H. M. (1941). Arch. Ophthal. (Chicago), 26, 626.

DUKE-EldER, S. (1950). "Text-book of Ophthalmology", vol. 4, p. 3847. Kimpton, London. JAval, E. (1868). "Du strabisme dans ses applications à la théorie de la vision". Thèse, Paris.

SCOBEe, R. G. (1952). “ "Oculorotary Muscles”, 2nd. ed., p. 303. Kimpton, London.

SWAN, K. C. (1950). " Strabismus Ophthalmic Symposium (1)”, ed. J. H. Allen, p. 107. Mosby, St. Louis.

Verhoeff, F. H. (1938). Arch. Ophthal. (Chicago), 19. 663.

\section{ADDITIONAL BIBLIOGRAPHY}

AdLer, F. H., and JACKSON, F. E. (1947). Arch. Ophthal. (Chicago), 38, 289.

ASHER, H. (1953). British Journal of Ophthalmology, 37, 37.

BIELSCHOWSKY, A. (1938, 1939). "Lectures on Motor Anomalies ". Ophthalmic Publishing Company, St. Louis.

Burian, H. M. (1947). Arch. Ophthal. (Chicago), 37, 336. (1951). Amer. J. Ophthal., 34, 237.

CAss, E. E. (1941). British Journal of Ophthalmology, 25, 565.

Davson, H. (1949). "The Physiology of the Eye ". Churchill, London.

Douglas, A. A. (1952). British Journal of Ophthaimology, 36, 169.

Gesell, A., IlG, F. L., and Bullis, G. E. (1949). "Vision: its Development in Infant and Child ". Hoeber, New York; Hamilton, London (1950).

GitToEs-DAVIES, R. (1952). Brit. orthoptic J., 9, 113.

HALDEN, U. (1952). "Fusional Phenomena in Anomalous Correspondence". Ejnar Munksgaard, Copenhagen.

JAMPOLSKy, A. (1951). Arch. Ophthal. (Chicago), 45, 18.

LYLE, T. KEITH (1950). " Worth and Chavasse's Squint", 8th ed. Baillière, Tindall and Cox, London.

, and JACKson, S. (1949). " Practical Orthoptics in the Treatment of Squint ", 3rd. ed. Lewis, London.

MaYou, S. (1947). Brit. orthoptic J., 4, 35.

Ogle, K. N., Mussey, F., and Prangen, A. De H. (1949). Amer. J. Ophthal., 32, 1069.

STEPHENSON, R. W. (1949). Trans. ophthal. Soc. U.K., 69, 549.

TrAVERS, T. à B. (1938). British Journal of Ophthalmology, $22,577$.

WERNER, H. (1942). Arch. Ophthal. (Chicago), 28, 834.

YoXALl, D. E. (1949). Trans. ophthal. Soc. U.K., 69, 559. 